\title{
Flavonoids Reduce Lipid Peroxides and Increase Glutathione Levels in Pooled Human Liver Microsomes (HLMs)
}

\author{
William Yaw Boadi1 ${ }^{*}$, Camille Stevenson², Dontrez Johnson ${ }^{2}$, Mohamed Adel Mohamed ${ }^{1}$ \\ ${ }^{1}$ Departments of Biological Sciences, Tennessee State University, Nashville, USA \\ ${ }^{2}$ Departments of Chemistry, Tennessee State University, Nashville, USA \\ Email: *wboadi@tnstate.edu
}

How to cite this paper: Boadi, W.Y., Stevenson, C., Johnson, D. and Mohamed, M.A. (2021) Flavonoids Reduce Lipid Peroxides and Increase Glutathione Levels in Pooled Human Liver Microsomes (HLMs). Advances in Biological Chemistry, 11, 283-295. https://doi.org/10.4236/abc.2021.116019

Received: October 26, 2021

Accepted: December 12, 2021

Published: December 15, 2021

Copyright $\odot 2021$ by author(s) and Scientific Research Publishing Inc. This work is licensed under the Creative Commons Attribution International License (CC BY 4.0).

http://creativecommons.org/licenses/by/4.0/

\section{(c) (i) Open Access}

\begin{abstract}
The effects of each of the flavonoids; genistein $(\mathrm{G})$, quercetin $(\mathrm{Q})$ and kaempferol $(\mathrm{K})$ at several doses on lipid peroxides (LP) and reduced glutathione (GSH) in pooled human liver microsomes (HLMs) were investigated following the oxidative damage for 4, 6, 18 and $24 \mathrm{hr}$. HLMs $(1 \mathrm{mg} / \mathrm{ml})$ were exposed to each of the above flavonoids at $0,5,10,15,20$ or $25 \mu \mathrm{M}$ and incubated for the respective times as previously stated. Our hypothesis was that HLMs exposed to the flavonoids for the respective exposure times can decrease LP and increase GSH in HLMs to better cope with the oxidative stress. The results of our studies indicate that each of the flavonoids significantly $(\mathrm{p}<$ $0.01)$ decreased LP compared to their respective controls. The highest decrease in LP was observed for K followed by Q and G. Significant increases $(p<0.01)$ in GSH were observed for the flavonoid doses tested with the highest levels observed for $\mathrm{Q}$ for the 24-hr. incubation. The findings suggest that the flavonoids modulate oxidative stress in HLMs by decreasing LP and such decreases in LPs may be due to the increasing and or the replenished levels of GSH in the said cells to better cope with the oxidative stress.
\end{abstract}

\section{Keywords}

Flavonoids, Glutathione (GSH), Human Liver Microsomes (HLMs), Lipid Peroxidation, Oxidative Stress

\section{Introduction}

Lipid peroxidation is a complex process occurring in aerobic cells and reflects 
the interaction between molecular oxygen and polyunsaturated fatty acids. Radicals are known to take part in lipid peroxidation, which causes food deterioration, aging organisms and cancer promotion [1] [2]. These reactive oxygen species (ROS) are reported to be involved in asthma, inflammation, arthritis, neurodegeneration, Parkinson's disease, mongolism and perhaps dementia [3] [4]. Antioxidants act as radical scavengers, inhibit lipid peroxidation and other free radical-mediated processes, thereby protecting the human body from several diseases attributed to reactions involving ROS [5] [6]. It has been reported that various phenolic antioxidants, such as flavonoids, tannins, coumarins, xanthones and more recently procyanidins scavenge ROS dose dependently, and thus are viewed as promising therapeutic drugs for ROS pathologies [7] [8] [9] [10].

Glutathione (GSH) has been reported as a potent endogenous antioxidant that helps to protect cells from several noxious stimuli including ROS [11]. Furthermore, several investigators have suggested that stress stimulates lipid peroxidation in several tissues which may also cause GSH reduction [12] [13] [14] [15] [16].

In our previous and recent studies, the effects of the flavonoids, genistein $(G)$, kaempferol (K), and quercetin (Q) on phospho tensin homolog (PTEN) levels in cancer cells (i.e., breast (BT549) and lung (A549)), human embroyonic kidney cells (HEK293), and levels of TBARS in peripheral blood mononuclear cells (PBMCs) were respectively investigated [17]. The results indicate that the single treatments of the cells with either G, K or Q increased total PTEN levels in a dose-dependent manner as well as in TBARS in PBMCs. Thus, consumption of foods containing polyphenols may help reduce the causes of factors related to the metabolic syndrome [18] [19] [20] and those associated with the anti-inflammatory mechanisms and improved antioxidant capacity [21] [22].

It has been reported that human liver microsomes (HLMs) provide the most convenient way to study cytochrome polymorphic (CYP)-mediated metabolism [23]. Microsomes are a subcellular fraction of tissue obtained by differential high-speed centrifugation [24]. As to how the flavonoids modulate the oxidative damage and GSH levels in HLMs are limited or non-existent. Thus, the purpose of the present studies was to investigate the single treatments of genistein $(G)$, kaempferol (K) and quercetin (Q) at $0,510,15,20$, and $25 \mu \mathrm{M}$ doses on TBARS and GSH in HLMs before and after the oxidative damage [17] [25] [26] [27]. Our studies sought to test the following hypotheses: 1) that, exposure of HLMs to either G, K or Q can decrease TBARS in those cells and better cope with oxidative stress. 2) That decreases in TBARS in HLMs following the exposure may be due to the concomitant increases in the intracellular levels of GSH. The proposed studies represent an effort to define how $\mathrm{G}, \mathrm{K}$ and $\mathrm{Q}$ modulate TBARS, a tumor promoter, [25] and GSH, a naturally occurring antioxidant, in HLMs cells following exposure to those insults over time. In terms of future directions, we will follow the lead set by the experimental results. 


\section{Materials and Methods}

\subsection{Chemicals}

Isoflavone kaempferol (3,5,7-trihydroxy-2-(4-hydroxyphenyl)-4H-1-benzopyran-4one, 98\% purity), and genistein (4',5,7-trihydroxy isoflavone, 98\%), and quercetin dihydrate $\left(3,3^{\prime}, 4^{\prime}, 5,7-\right.$-Pentahydroxyflavone dihydrate, 98\%) were from Sigma-Aldrich (St. Louis, MO). Human liver microsomes (HLMs) from pooled individual human donors' liver, ferrous chloride tetrahydrate $\left(\mathrm{FeCl}_{2} \cdot 4 \mathrm{H}_{2} \mathrm{O}\right.$, purity, $\left.99 \%\right)$, phosphate-buffered saline (PBS, 0.1 M), dimethyl sulfoxide (DMSO, 99\% purity) and $\mathrm{H}_{2} \mathrm{O}_{2}$ were purchased from Fisher Scientific Suwanee, GA. Double deionized water was purified using a Milli-Q system (Millipore Corporation, MA).

\subsection{Preparation of Standard and Stock Solutions}

The flavonoids were dissolved in DMSO. The respective solutions were further diluted (between 50 - 100 times, depending on the dose needed) with DMSO before adding to the incubation mixture. The final DMSO concentration in the incubation mixture was $0.05 \% \mathrm{v} / \mathrm{v}$ [17].

\subsection{Treatment of HLMs with the Flavonoids}

A typical incubation mixture was prepared in a total volume of $200 \mu \mathrm{l}$ with HLMs $(1 \mathrm{mg} / \mathrm{ml})$, with the respective single treatments, $\mathrm{G}, \mathrm{K}$ or $\mathrm{Q}$ at $0,5,10,15$, 20 , and $25 \mu \mathrm{M}$ respectively. All the controls and samples following the treatments were cultured at $37^{\circ} \mathrm{C}$ for $4,6,18$ and $24 \mathrm{hr}$. respectively.

\subsection{Antioxidant Activity Testing of Flavonoids in HLMs}

Antioxidative activity as described by [28] was used with some modifications. HLMs $(1 \mathrm{mg} / \mathrm{ml})$ in a total reaction volume of $200 \mu \mathrm{l}$ of PBS were incubated with $\mathrm{Fe}^{2+}(50 \mu \mathrm{M})$ ions [29] and $\mathrm{H}_{2} \mathrm{O}_{2}(0.01 \mathrm{mM})$ with and without flavonoid sample at $0,5,10,15,20$ and $25 \mu \mathrm{M}$ for each of the three flavonoids and were tested in this study for $4,6,18$ and 24 hr. respectively at $5 \% \mathrm{CO}_{2}$.

\subsection{Reagents Effect on HLMs Cell Growth and Viability}

HLMs were treated in separate experiments to determine whether DMSO (0.05\%), $\mathrm{H}_{2} \mathrm{O}_{2}(0.01 \mathrm{mM})$ and $\mathrm{Fe}^{2+}(50 \mu \mathrm{M})$ ions were affecting cell growth and viability that might compromise the levels of TBARS and GSH. HLMs ( $1 \mathrm{mg} / \mathrm{ml})$ per tube were incubated respectively with DMSO, $\mathrm{H}_{2} \mathrm{O}_{2}$, and $\mathrm{Fe}^{2+}$ ions, as stated above for $24 \mathrm{hr}$. Cell viability and number were assessed as we have previously reported [26] [27].

\subsection{Preparation of Samples after Treatments with the Flavonoids}

Following the incubations, samples were centrifuged in a refrigerated Eppendorf table-top centrifuge (Model \# $5804 \mathrm{R}$, Suwanee, GA) at $4^{\circ} \mathrm{C}$ for $10 \mathrm{~min}$ at 3000 RPM. HLMs following the incubations were rinsed with sterile phosphate buf- 
fered saline (PBS) to remove any reagents and prepared as previously reported [17].

\subsection{Analysis of Lipid Peroxides in HLMs}

The method as previously reported [17] was used with some slight modifications. TBARS standard curves were used to determine the levels of lipid peroxides in the samples.

\subsection{Analysis of Reduced Glutathione (GSH) in HLMs}

Reduced GSH was analyzed as described [30] with some modifications as prescribed by the Calbiochem GSH Assay Kit (No. 354102). Following the incubation, cells centrifuged at $3000 \times \mathrm{g}$ for $10 \mathrm{~min}$ at $4^{\circ} \mathrm{C}$ in a refrigerated table top Eppendorf centrifuge (Fisher Scientific, Suwanee GA) and resuspended in $300 \mu \mathrm{l}$ of 5\% metaphosphoric acid (MPA). Cells were sonicated under ice for 30 seconds using a cell dismembrator (Fisher Scientific, Suwanee GA) at a setting of 3. The homogenate was then centrifuged at $3000 \times \mathrm{g}$ for 10 minutes at $4^{\circ} \mathrm{C}$. The resulting supernatant was removed and stored at $-70^{\circ} \mathrm{C}$ until used for the analysis of GSH. GSH levels in cells were calculated from the standard curve using GSH prepared in 5\% MPA (freshly prepared) as standard and expressed in $\mu \mathrm{M}$.

\subsection{Statistical Analysis}

Results are expressed as means of \pm SD. Statistical significance was determined as previously described (Boadi et al. 2014). Each value in all figures represents the mean for each dose of the single flavonoid and TBARS and GSH tested, which was assayed in triplicates.

\section{Results}

\subsection{Effects of Exposure of Flavonoids on Lipid Peroxides in HLMs for 4, 6, 18 and $24 \mathrm{Hr}$}

Figures 1-4 show the effects of the respective exposure of K, G and Q on TBARS in HLMs following the respective incubation times.

\subsection{Effects of the Acute Exposure of Flavonoids on TBARS in HLMs for 4 and 6 Hrs}

Figure 1 and Figure 2 show the respective TBARS in HLMs for G, Q and $\mathrm{K}$ treatments for the 4 and $6 \mathrm{hr}$ incubation periods. TBARS remained the same for the untreated (U) HLMs. However, TBARS decreased significantly $(\mathrm{p}<0.01)$ for all the 3 flavonoids tested in comparison to their respective controls. The decreases in TBARS were higher for $\mathrm{K}$ treated samples followed by $\mathrm{G}$ and $\mathrm{Q}$. A similar significant decrease $(\mathrm{p}<0.01)$ in TBARS was observed for the $6 \mathrm{hr}$. treatments (Figure 2). However, the decreases in TBARS were not dose-dependent (Figure 1 and Figure 2). Significant decreases in TBARS were observed at the 5 $\mu \mathrm{M}$ for all the flavonoids irrespective of the incubation period. In comparing the 


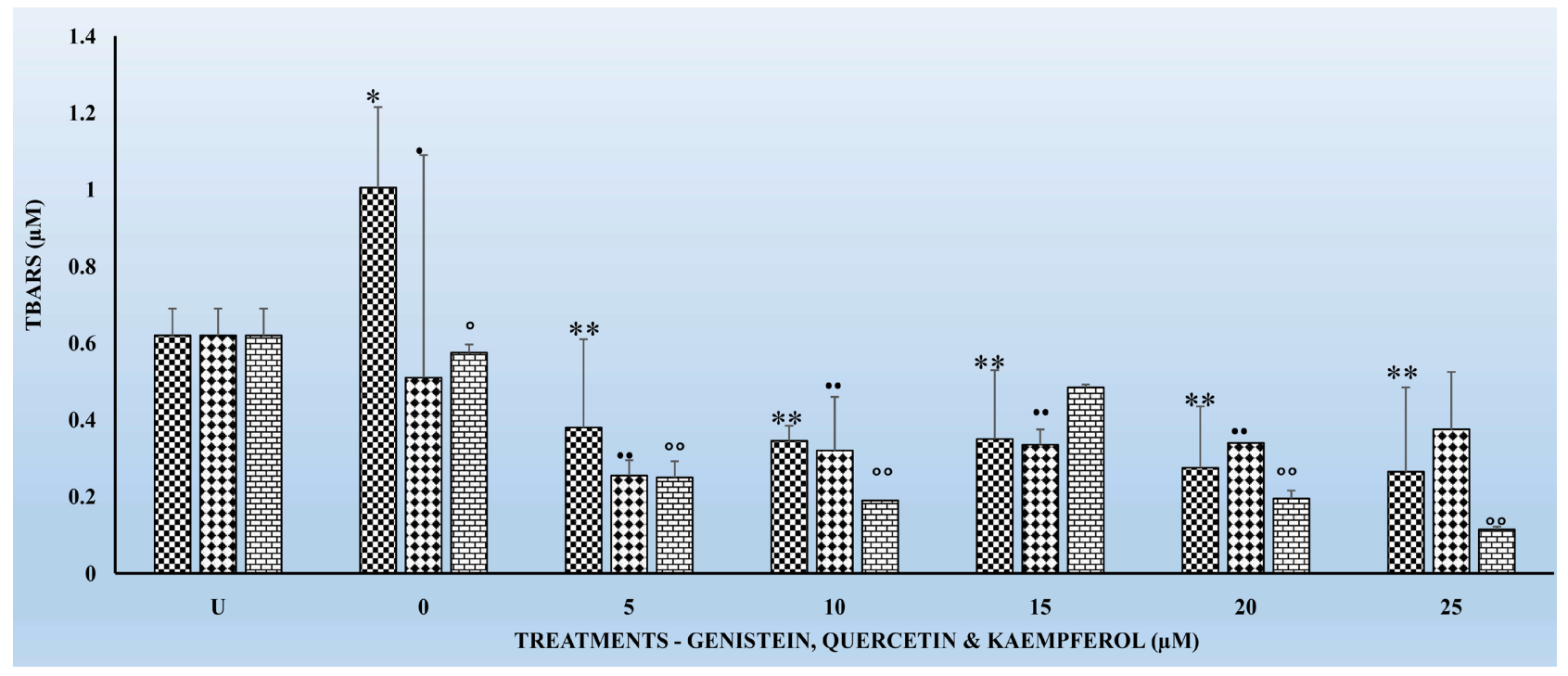

Figure 1. The effects several doses $(0,5,10,15,20$, and $25 \mu \mathrm{M})$ each of genistein $(\mathrm{G})$, quercetin (Q) and kaempferol (K) on thiobarbituric reactive substances (TBARS) in pooled human liver microsomes (HLMs), following incubation at $37^{\circ} \mathrm{C}$ and $5 \% \mathrm{CO}_{2}$ for $4 \mathrm{~h}$. Each bar chart for each flavonoid \pm standard deviation in this and other figures (i.e., Figures 2-4) in this article represent mean the for 3 different experiments for each dose level of G, Q and K tested and, which was assayed in triplicates. Statistical significances denoted by asterisk in Figures 2-4 are shown as comparison between the respective control (i.e., without G, Q and K) and G, Q and K HLMs treated subgroups. Vertical bars in this and other figures denote standard deviation. The X-axis labels for Figures 2-4 are defined as follows: $U$ means untreated cells samples; 0 means control cell samples not treated with G, Q and K; 5, $10,15,20$, and $25 \mu \mathrm{M}$ means cell samples were each treated with the respective dose of G, Q and $\mathrm{K}$ for $4,6,18$ and 24 h.

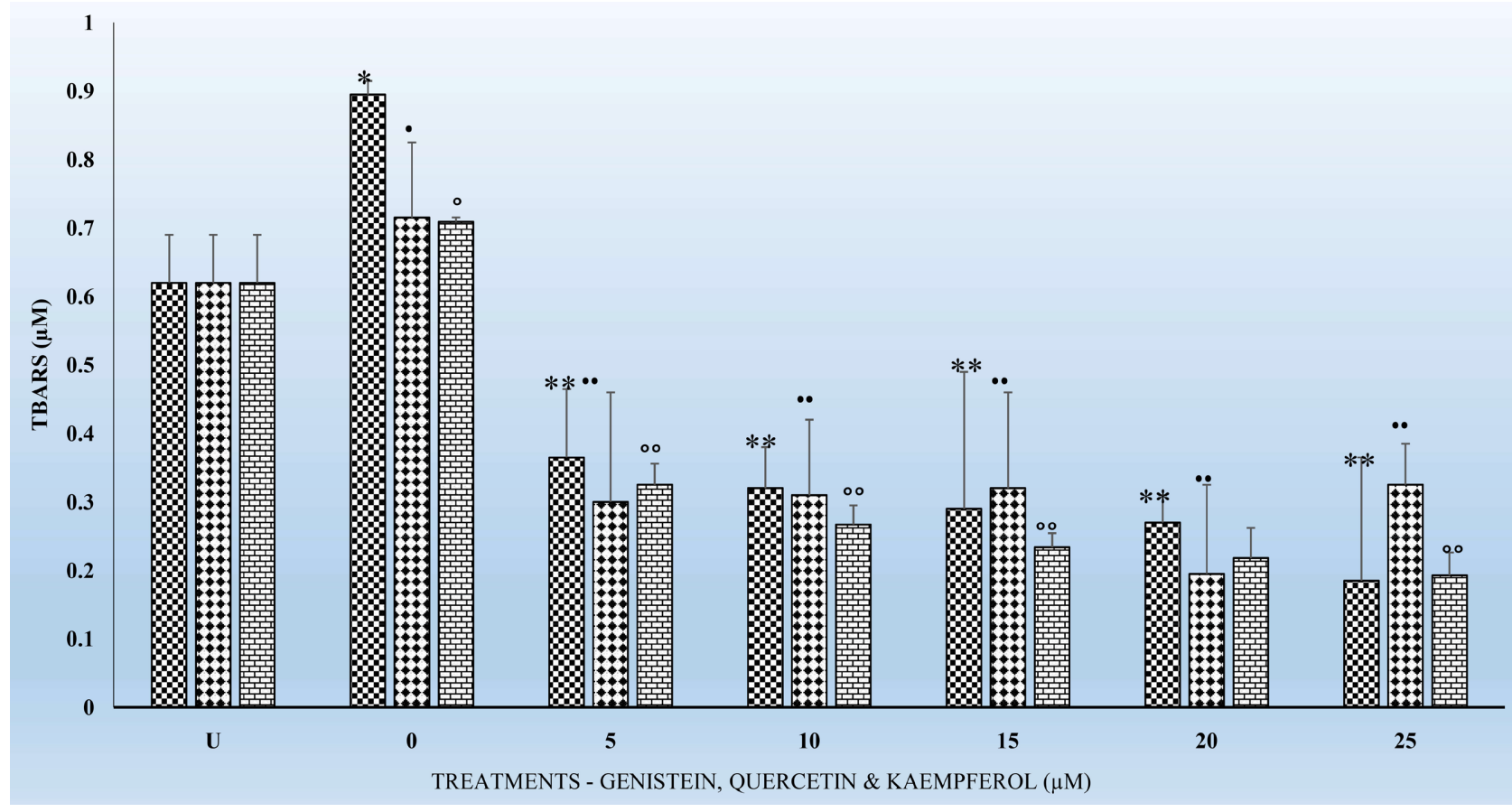

Figure 2. The effects several doses $(0,5,10,15,20$, and $25 \mu \mathrm{M})$ each of $\mathrm{G}$, Q and $\mathrm{K}$ on TBARS in HLMs, following incubation at $37^{\circ} \mathrm{C}$ and $5 \% \mathrm{CO}_{2}$ for $6 \mathrm{~h}$. For comparison and statistical differences see Figure 1.

decreases in TBARS for the $4 \mathrm{hr}$. (Figure 1) to that of the $6 \mathrm{hr}$. (Figure 2), $\mathrm{K}$ decreased TBARS more compared to either $\mathrm{G}$ or $\mathrm{Q}$ for the respective time periods. 


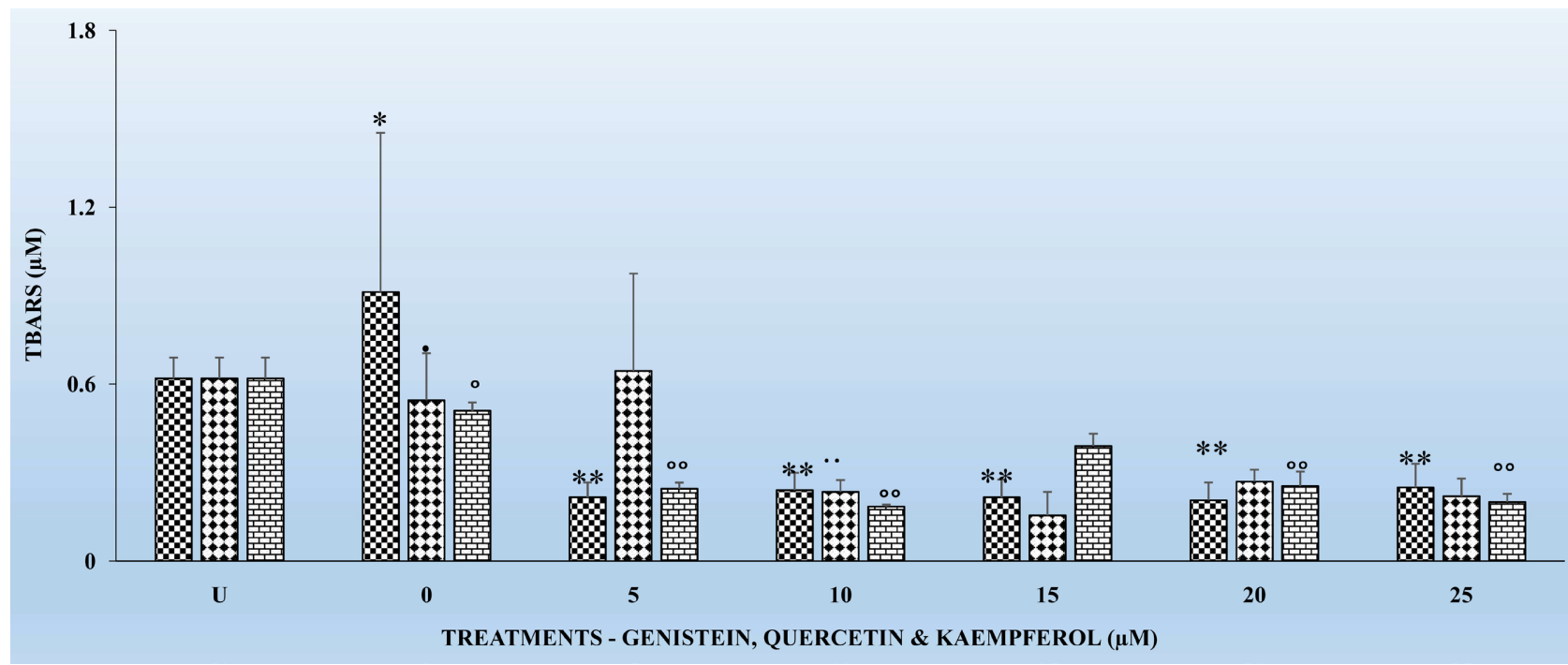

Figure 3. The effects several doses $(0,5,10,15,20$, and $25 \mu \mathrm{M})$ each of $\mathrm{G}, \mathrm{Q}$ and $\mathrm{K}$ on TBARS in HLMs, following incubation at $37^{\circ} \mathrm{C}$ and $5 \% \mathrm{CO}_{2}$ for $18 \mathrm{~h}$. For comparison and statistical differences see Figure 1.

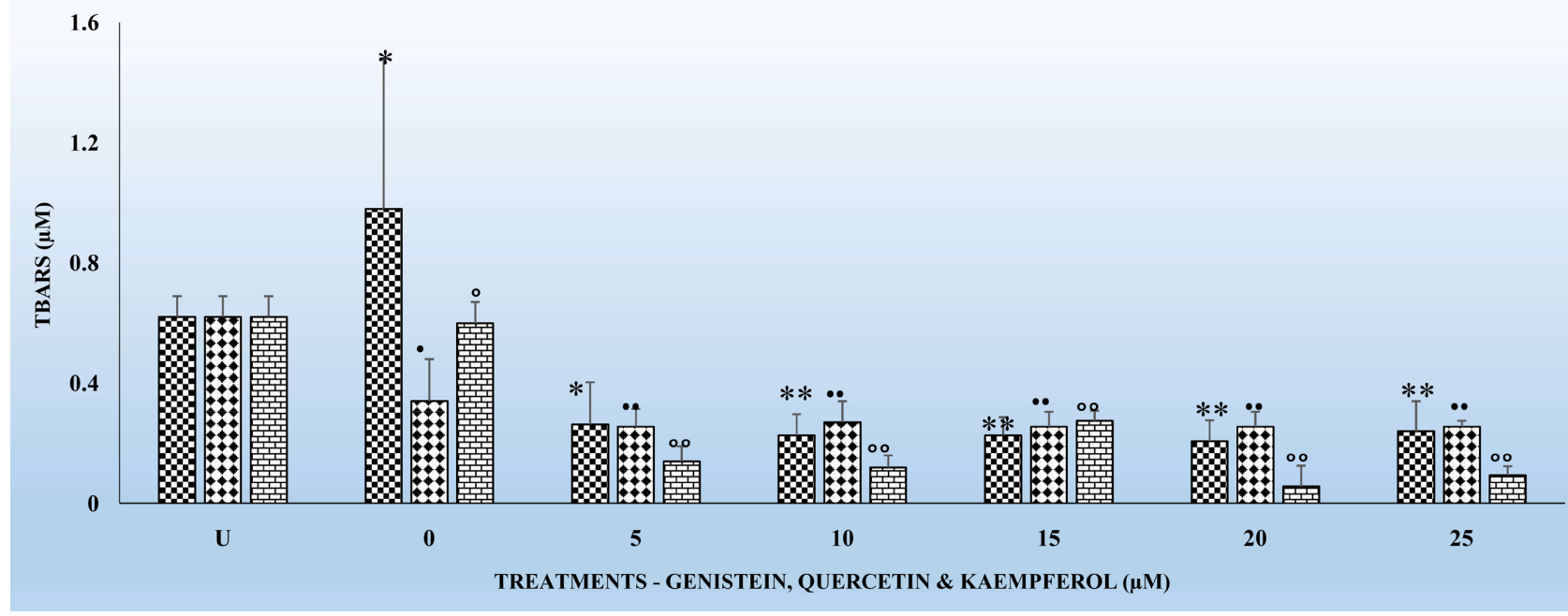

Figure 4. The effects of several doses $(0,5,10,15,20$, and $25 \mu \mathrm{M})$ each of $\mathrm{G}$, Q and $\mathrm{K}$ on TBARS in HLMs, following incubation at $37^{\circ} \mathrm{C}$ and $5 \% \mathrm{CO}_{2}$ for $24 \mathrm{~h}$. For comparison and statistical differences see Figure 1.

\subsection{Effects of the Chronic Exposure of Flavonoids on TBARS in HLMs for 18 and $24 \mathrm{Hr}$}

Figure 3 and Figure 4 show the effects of the respective exposure of the flavonoids on TBARS in HLMs following incubation for 18 and $24 \mathrm{hr}$. As previously observed for the 4 and $6 \mathrm{hr}$. incubation periods, TBARS, remained the same for the untreated (U) HLMs samples. However, TBARS decreased significantly ( $\mathrm{p}<$ $0.01)$ for each of the flavonoids tested in comparison to their respective controls. The significant decreases $(\mathrm{p}<0.01)$ in TBARS for the $24 \mathrm{hr}$. treatments (Figure 4) were higher compared to the $18 \mathrm{hr}$. Significant $(\mathrm{p}<0.05)$ decreases in TBARS were observed as early at the $5 \mu \mathrm{M}$ for all the respective flavonoids. $\mathrm{K}$ again as previously observed for the 4 and $6 \mathrm{hr}$. (Figure 1 and Figure 2) decreased TBARS more compared to $\mathrm{G}$ and $\mathrm{Q}$ for the above time periods. 


\subsection{Effects of Flavonoids on GSH Levels in HLMs Following Incubations for 4, 6, 12 and $18 \mathrm{Hr}$}

Tables 1-3 show the effects of the single treatments of G, Q and K 0, 5, 10, 15, 20 and $25 \mu \mathrm{M}$ on GSH levels in HLMs following oxidation by the Fenton's pathway and incubation for 4, 618 and 24 h respectively. GSH levels increased ( $p<0.05$ ) for G (Table 1) at the $10-25 \mu \mathrm{M}$; Q and $\mathrm{K}$ (Table 2 and Table 3 ) at the $5-25$ $\mu \mathrm{M}$ doses compared to their respective controls and were time dependent. Levels of GSH were sustained and replenished during the oxidative damage for the Q, $\mathrm{G}$ and $\mathrm{K}$ treated samples in comparison to their respective controls. Despite the significant increases $(\mathrm{p}<0.05)$ in GSH for $\mathrm{Q}$ at the said doses, each of the flavonoids were capable of replenishing GSH levels in cells to combat the stress. On comparative basis Q appears to have the greatest effect in increasing GSH levels, followed by $\mathrm{G}$ and $\mathrm{K}$.

Table 1. GSH Levels ( $\mu$ moles/mg protein) in HLMs following exposure to genistein for 4, 6, 18 and 24 hr. respectively. Each cell for each flavonoid \pm standard deviation in this and other tables (i.e., Table 2 and Table 3 ) in this article represent mean the for 3 different experiments for each dose level of $\mathrm{G}$ tested and, which was assayed in triplicates. Statistical significances denoted by letters, in Table 1 are shown as comparison between the respective control (i.e., without G) and GHLMs treated subgroups for the respective incubation periods.

\begin{tabular}{ccccccc}
\hline Incubation & 0 & 5 & 10 & 15 & 20 & $25(\mu \mathrm{M})$ \\
\hline 4 & $1.15 \pm 0.16$ & $3.41 \pm 0.41$ & $3.11 \pm 0.24^{\mathrm{a}}$ & $3.69 \pm 0.38^{\mathrm{a}}$ & $2.19 \pm 0.24^{\mathrm{a}}$ & $4.07 \pm 0.24^{\mathrm{a}}$ \\
6 & $1.29 \pm 0.03$ & $4.74 \pm 0.99$ & $3.98 \pm 0.50^{\mathrm{b}}$ & $5.78 \pm 0.46^{\mathrm{b}}$ & $4.79 \pm 0.87^{\mathrm{b}}$ & $5.34 \pm 1.32^{\mathrm{a}}$ \\
18 & $1.10 \pm 0.12$ & $3.40 \pm 0.11$ & $3.24 \pm 0.20^{\mathrm{cd}}$ & $3.19 \pm 0.60^{\mathrm{bc}}$ & $3.18 \pm 1.15$ & $6.80 \pm 0.75^{\mathrm{b}}$ \\
24 & $1.07 \pm 0.05$ & $4.57 \pm 0.21$ & $5.74 \pm 0.19^{\mathrm{d}}$ & $3.92 \pm 0.34^{\mathrm{bd}}$ & $4.14 \pm 0.62^{\mathrm{c}}$ & $7.14 \pm 0.54^{\mathrm{b}}$ \\
\hline
\end{tabular}

Table 2. GSH Levels ( $\mu$ moles/mg protein) in HLMs following exposure to quercetin for 4, 6, 18 and 24 hr. respectively. For comparison and statistical differences see Table 1 .

\begin{tabular}{ccccccc}
\hline Incubation & 0 & 5 & 10 & 15 & 20 & $25(\mu \mathrm{M})$ \\
\hline 4 & $1.11 \pm 0.16$ & $3.41 \pm 0.41^{\mathrm{a}}$ & $3.51 \pm 0.24^{\mathrm{a}}$ & $3.69 \pm 0.38^{\mathrm{a}}$ & $4.99 \pm 0.24^{\mathrm{a}}$ & $4.07 \pm 0.24^{\mathrm{a}}$ \\
6 & $1.09 \pm 0.03$ & $4.74 \pm 0.99$ & $4.98 \pm 0.50^{\mathrm{b}}$ & $6.78 \pm 0.46^{\mathrm{b}}$ & $9.79 \pm 0.87^{\mathrm{b}}$ & $11.34 \pm 1.32^{\mathrm{b}}$ \\
18 & $1.11 \pm 0.12$ & $5.40 \pm 0.11^{\mathrm{b}}$ & $6.24 \pm 0.23^{\mathrm{c}}$ & $6.19 \pm 0.63^{\mathrm{b}}$ & $10.48 \pm 1.15^{\mathrm{c}}$ & $12.80 \pm 0.75^{\mathrm{c}}$ \\
24 & $1.17 \pm 0.05$ & $6.57 \pm 0.21^{\mathrm{c}}$ & $7.74 \pm 0.19^{\mathrm{d}}$ & $7.92 \pm 0.34^{\mathrm{c}}$ & $11.14 \pm 0.62^{\mathrm{d}}$ & $14.14 \pm 0.54^{\mathrm{d}}$ \\
\hline
\end{tabular}

Table 3. GSH Levels ( $\mu$ moles/mg protein) in HLMs following exposure to kaempferol for 4, 6, 18 and 24 hr. respectively. For comparison and statistical differences see Table 1 .

\begin{tabular}{ccccccc}
\hline Incubation & 0 & 5 & 10 & 15 & 20 & $25(\mu \mathrm{M})$ \\
\hline 4 & $1.15 \pm 0.16$ & $3.41 \pm 0.41^{\mathrm{a}}$ & $3.51 \pm 0.24^{\mathrm{a}}$ & $3.69 \pm 0.38^{\mathrm{a}}$ & $2.99 \pm 0.24^{\mathrm{a}}$ & $4.77 \pm 0.24^{\mathrm{a}}$ \\
6 & $1.29 \pm 0.03$ & $4.74 \pm 0.99$ & $5.98 \pm 0.50^{\mathrm{b}}$ & $5.78 \pm 0.46^{\mathrm{b}}$ & $6.79 \pm 0.87^{\mathrm{b}}$ & $8.34 \pm 1.32^{\mathrm{b}}$ \\
18 & $1.11 \pm 0.12$ & $1.40 \pm 0.11^{\mathrm{c}}$ & $1.24 \pm 0.23^{\mathrm{c}}$ & $2.19 \pm 0.63^{\mathrm{c}}$ & $3.48 \pm 1.15^{\mathrm{bc}}$ & $2.80 \pm 0.75^{\mathrm{bc}}$ \\
24 & $1.27 \pm 0.05$ & $1.57 \pm 0.21^{\mathrm{d}}$ & $1.74 \pm 0.19^{\mathrm{d}}$ & $1.92 \pm 0.34^{\mathrm{d}}$ & $3.14 \pm 0.62^{\mathrm{c}}$ & $14.14 \pm 0.54^{\mathrm{d}}$ \\
\hline
\end{tabular}




\subsection{Relationship between Lipid Peroxides and GSH Levels in HLMs Following the Exposure to the Flavonoids}

One of the hypotheses in this study was to test whether there is any correlation between exposure of HLMs to the flavonoids for 6, 12, 18 and $24 \mathrm{hr}$. can offer better protection to HLMs through decreased TBARS and increased and replenished GSH over time. It is interesting to report that treatments of HLMs to flavonoids and after the oxidative damage were as effective in significantly $(\mathrm{p}<$ $0.05)$ reducing TBARS (Figures $1-3)$ as well as significantly increasing $(\mathrm{p}<01)$ GSH levels (Tables 1-3) over time. The decreases in TBARS as well as the increases in GSH were highest for Q followed by K and G.

\section{Discussion}

\subsection{Lipid Peroxides and Flavonoids as Antioxidants}

ROS formed in cells, including singlet oxygen, can oxidize several cellular constituents like lipids, proteins and DNA. Lipid oxidation occurs in membranes, especially in the intracellular ones. During lipid peroxidation many different products, e.g. aldehydes, peroxides and ROS are formed. The direct effect of lipid peroxidation is the membrane destruction. Secondary effects include the interaction of lipid peroxidation reaction products with other cellular components, e.g. the reaction of aldehydes with DNA, which can result in mutagenicity or carcinogenicity [31] [32]. The protective effects of flavonoids have been attributed to a wide variety of mechanisms, including modulating enzyme activities resulting in the decreased carcinogenicity of xenobiotics [27] [32] [33].

\subsection{Studies Purpose and Hypothesis}

As to how the flavonoids modulate the mechanisms of the levels of TBARS following the oxidative damage in HLMs have not been well studied or very non-existent in the literature. Thus, the purpose of the present study was two-fold. First, to investigate the effects of exposure of HLMs to each of G, K and Q at 0, 5 $10,15,20$, and $25 \mu \mathrm{M}$ on lipid peroxides measured as, TBARS. And second, to study if there is any correlation between the levels of LPs and GSH following the exposure to these flavonoids and the oxidative damage. Our studies sought to test the following two hypotheses: 1) that, exposure of HLMs to either G, K or $\mathrm{Q}$ can decrease TBARS in those cells and to better cope with oxidative stress. 2) That, exposure of HLMs to either G, K or Q can help replenish GSH in those cells and better cope with oxidative stress. The HLMs model was selected because it serves as a good system to measure antioxidant activity and are close to the in vivo situation where both aqueous and lipid phases are present [34].

\subsection{Effects of Genistein, Kaempferol and Quercetin on Lipid Peroxides}

The findings in this study indicate that, TBARS, decreased significantly $(\mathrm{p}<$ 
0.01) for each of the flavonoids in comparison to their respective controls (Figures 1-4). The decreased TBARS as observed in the current studies is similar, to that reported by Menéndez et al. [35]. In that studies, the authors observed inhibition of rat microsomal lipid peroxides by the oral administration of D002, a compound, made up of a mixture of higher primary alcohols purified from bee wax. The authors attributed the inhibition in the lipid peroxides to the actions of superoxide dismutase (SOD), catalase and glutathione peroxidase (GSH-Px) which represent an efficient defense system against hazards of lipid peroxidation [35].

\subsection{Relationship between Lipid Peroxides and Glutathione}

We have observed increased levels of GSH for all the tested flavonoids (Tables 1-3) following the oxidative stress. The above seem to suggest that these compounds must have helped the HLMs to regenerate enough GSH to offset the oxidative stress and probably through the GSH-Redox system. Increases in GSH in the present studies lend support to our previous studies where we demonstrated that the flavonoids can upregulate the GSH-Redox system thereby reducing the damaging effects of ROS [30]. Such observations are like those by Menéndez et al. [35] who attributed that to the actions of SOD, catalase and GSH-Px against hazards of lipid peroxidation. On the contrary, studies by Wattenberg et al. [36] on the CYP system have shown different modulatory effects of flavonoids activity both in vitro and in vivo. The authors suggested that exposure of cells to flavonoids might have caused the induction of either phase I or phase II enzymes that can result in increased detoxification of carcinogens [36] [37]. We are currently conducting similar experiments to substantiate if there is any correlation between the increased GSH and that of some phase I or phase II enzymes following exposure of the HLMs to the flavonoids that might partly have contributed to the decreased TBARS.

\subsection{Effects of the Incubation Periods on Lipid Peroxides}

It is also very interesting to know that significant $(\mathrm{p}<0.01)$ decreases in TBARS were observed at the $5 \mu \mathrm{M}$ for the tested flavonoids irrespective of the incubation period (Figures 1-4). The above observation is very interesting and at variance with what we have seen in our previous studies in other cell types [17] [27] [32] where decreases in TBARS were time- and dose-dependent. The only plausible explanation for such observations in HLMs may be three-fold. First, it is possible that the effects of flavonoids on enzymes are generally dependent on the concentrations of the flavonoids present. Second, the bioavailability of the different flavonoids in the cells may be low which not reflect the concentrations tested under in vitro conditions [33]. Furthermore, the HLMs that we have used in the current studies were from pooled human donors. Thus, the marked interindividual variability in drug-metabolizing enzymes as result of genetic and other environmental factors [33] might have attributed to our current observations. Nevertheless, the antioxidant activities of flavonoids against metal-induced lipid pe- 
roxidation are probably a consequence of their metal-chelating and free radical scavenging activities [38].

\section{Conclusion}

We have employed single flavonoid treatments $\mathrm{G}, \mathrm{Q}$ and $\mathrm{K}$ at different concentrations to reduce the levels of TBARS and to increase GSH levels in HLMs. By using the single treatments of these flavonoids over time the cellular and biological activities based on the decreased TBARS and increased intracellular levels of GSH would be useful for developing health supplements and/or therapeutic drugs against diseases associated with the oxidative damage.

\section{Acknowledgements}

The authors wish to acknowledge the help of all the undergraduate students who helped in diverse ways with the planning and execution of all experiments. This study did not involve the use of human subjects or experimental animals.

\section{Conflicts of Interest}

The authors report no conflict of interest. The authors alone are responsible for the content and writing of the article.

\section{Funding}

The financial support of the Maximizing Access to Research Careers Undergraduate Student Training in Academic Research (MARC U-STAR) grant number, 5T34GM007663, and that of the Student Opportunities for Advancement in Research Skills (SOARS) grant through the United States Department of Education (DOE) are greatly appreciated.

\section{References}

[1] Cerruti, P.A. (1994) Oxy-Radicals and Cancer. The Lancet, 344, 862-863. https://doi.org/10.1016/S0140-6736(94)92832-0

[2] Ashok, B.T, and Ali, R. (1999) The Aging Paradox: Free Radical Theory of Aging. Experimental Gerontology, 34, 293-303. https://doi.org/10.1016/S0531-5565(99)00005-4

[3] Adams, J.D. and Odunze, I.N. (1991) Oxygen Free Radicals and Parkinson's Disease. Free Radical Biology and Medicine, 10, 161-169. https://doi.org/10.1016/0891-5849(91)90009-R

[4] Perry, G., Raina, A.K., Nunomura, A., Wataya, T., Sayre, L.M. and Smith, M.A. (2000) How Important Is Oxidative Damage? Lessons from Alzheimer's Disease. Free Radical Biology and Medicine, 28, 831-834. https://doi.org/10.1016/S0891-5849(00)00158-1

[5] Nizamuddin, A. (1987) NADPH-Dependent and $\mathrm{O}_{2}$-Dependent Lipid Peroxidation. Biochemistry Education, 15, 58-62. https://doi.org/10.1016/0307-4412(87)90083-5

[6] Takao, T., Kitatani, F., Watanabe, N., Yagi, A. and Sakata, K. (1994) A Simple Screening Method for Antioxidants and Isolation of Several Antioxidants Produced 
by Marine Bacteria from Fish and Shellfish. Bioscience, Biotechnology, and Biochemistry, 58, 1780-1783. https://doi.org/10.1271/bbb.58.1780

[7] Lugasi, A. (2000) Potentially Health-Protective Effects of Flavonoids Having Food Origin. Orvosi Hetilap, 141, 1751-1760.

[8] Potterat, O. (1997) Antioxidants and Free Radical Scavengers of Natural Origin. Current Organic Chemistry, 1, 415-440.

[9] Yokozawa, T., Dong, E., Liu, Z.W. and Shimizu, M. (1997) Antioxidative Activity of Flavones and Flavonols in Vitro. Phytochemistry Research, 11, 446-449. https://doi.org/10.1002/(SICI)1099-1573(199709)11:6\%3C446::AID-PTR128\%3E3.0 .CO;2-8

[10] Saint-Cricq de Gaulejac, N., Provost, C. and Vivas, N. (1999) Comparative Study of Polyphenol Scavenging Activities Assessed by Different Methods. Journal of Agriculture and Food Chemistry, 47, 425-431. https://doi.org/10.1021/jf980700b

[11] Simmons, H.F., James, R.C., Harbison, R.D. and Roberts, S.M. (1990) Depression of Glutathione by Cold Restraint in Mice. Toxicology, 161, 59-71.

https://doi.org/10.1016/0300-483X(90)90007-4

[12] Yeğen, B., Dedeoğlu, A., Aykaç, I., Okta, S. and Yalçin, S. (1990) Effect of Cold-Restraint Stress on Glutathione and Lipid Peroxide Levels in the Liver and Glandular Stomach of Rats. Pharmacology Research, 22, 45-48. https://doi.org/10.1016/1043-6618(90)90742-V

[13] Capel, I.D., Dorrell, H.M. and Smallwood, A.E. (1983) The Influence of Cold-Restraint Stress on Some Components of the Antioxidant Defense System in the Tissues of Rats of Various Ages. Journal of Toxicology and Environmental Health, 11, 425-436. https://doi.org/10.1080/15287398309530356

[14] Ceremuzynski, L., Barcikowski, B., Lewicki, Z., Wutzen, J., Gordon-Majsvak, W., Famulski, K.S., Klos, J. and Herbaczynska-Cedro, K. (1991) Stress-Induced Injury of Pig Myocardium is Accompanied by Increased Lipid Peroxidation and Depletion of Mitochondrial ATP. Experimental Pathology, 43, 213-220. https://doi.org/10.1016/S0232-1513(11)80120-9

[15] Juranek, I., Bauer, V. and Horakova, L. (1992) Influence of Acute Stress on Lipid Peroxidation in Vivo. Pharmazie, 47, 716-717.

[16] Kovacs, P., Juranek, I., Stankovicova, T. and Svec, P. (1996) Lipid Peroxidation during Acute Stress. Pharmazie, 51, 51-53.

[17] Boadi, W.Y., Garcia, A.S. and Myles, E.L. (2020) Phospho Tensin Homolog (PTEN) in Cancer Cells and Lipid Peroxides in Peripheral Blood Mononuclear Cells (PBMCs) Following Exposure to Flavonoids. Journal of American College of Nutrition, 39, 135-146. https://doi.org/10.1080/07315724.2019.1616234

[18] Heidemann, C., Scheidt-Nave, C., Richter, A. and Mensink G.B. (2011) Dietary Patterns Are Associated with Cardio Metabolic Risk Factors in a Representative Study Population of German Adults. British Journal of Nutrition, 106, 1253-1262. https://doi.org/10.1017/S0007114511001504

[19] Kouki, R., Schwab, U., Hassinen, M., Komulainen, P., Heikkila, H. and Lakka, T.A. (2011) Food Consumption, Nutrient Intake and the Risk of Having Metabolic Syndrome: The DR's EXTRA Study. European Journal of Clinical Nutrition, 65, 368-377. https://doi.org/10.1038/ejcn.2010.262

[20] Esmaillzadeh, A., Kimiagar, M., Mehrabi, Y., Azadbakht, L., Hu, F.B. and Willett, W.C. (2006) Fruit and Vegetable Intakes, C-Reactive Protein, and the Metabolic Syndrome. American Journal of Clinical Nutrition, 84, 1489-1497. 
https://doi.org/10.1093/ajcn/84.6.1489

[21] Abete, I., Goyenechea, E., Zulet, M.A. and Martinez, J.A. (2011) Obesity and Metabolic Syndrome: Potential Benefit from Specific Nutritional Components. Nutrition Metabolism and Cardiovascular Disease, 21, B1-B15. https://doi.org/10.1016/j.numecd.2011.05.001

[22] Hermsdorff, H.H., Zulet, M.A., Puchau, B. and Martinez, J.A. (2010) Fruit and Vegetable Consumption and pro Inflammatory Gene Expression from Peripheral Blood Mononuclear Cells in Young Adults: A Translational Study. Nutrition and Metabolism, 7, Article No. 42. https://doi.org/10.1186/1743-7075-7-42

[23] Jia, L. and Liu, X. (2007) The Conduct of Drug Metabolism Studies Considered Good Practice (II): In Vitro Experiments. Current Drug and Metabolism, 8, 822-829. https://doi.org/10.2174/138920007782798207

[24] Jia, L., Yu, L., Linnik, D.M. and Jack, R.M. (2001) Biostability and Pharmacokinetics of LJP 920, an Octameric Gal ( $\alpha 1-3)$ Gal Conjugate for the Inhibition of Xenotransplantation Rejection. Journal of Pharmacy and Pharmacology, 53, 999-1005. https://doi.org/10.1211/0022357011776243

[25] Boadi, W.Y., Iyere, P.A. and Adunyah, S.E. (2003) Effect of Quercetin and Genistein on Copper- and Iron-Induced Lipid Peroxidation in Methyl Linolenate. Journal of Applied Toxicology, 23, 363-369. https://doi.org/10.1002/jat.933

[26] Boadi, W.Y., Iyere, P.A. and Adunyah, S.E. (2005) In Vitro Exposure to Quercetin and Genistein Alters Lipid Peroxides and Prevents the Loss of Glutathione in $\mathrm{Hu}$ man Progenitor Mononuclear (U937) Cells. Journal of Applied Toxicology, 25, 82-88. https://doi.org/10.1002/jat.1049

[27] Boadi, W.Y. and Lo, A. (2014) Quercetin and Kaempferol but Not Glutathione Inhibit Lysine, Arginine and Increase Cysteine Residues in Hemoglobin and Myoglobin. The Journal of Free Radical Antioxidants, 141, 386-398.

[28] Stinson, T.J., Jaw, S., Jeffrey, E.H. and Plewa, M. (1992) The Relationship between Nickel Chloride-Induced Peroxidation and DNA Strand Breakage in Rat Liver. Toxicology Applied Pharmacology, 117, 98-103.

https://doi.org/10.1016/0041-008X(92)90222-E

[29] Kennedy, L.J., Moore, K., Caufield, J.L., Tannenbaum, S.R. and Dedon, P.C. (1997) Quantitation of 8-Oxoguanine and Strand Breaks Produced by four Oxidizing Agents. Chemical Research and Toxicology, 10, 386-392. https://doi.org/10.1021/tx960102w

[30] Boadi, W.Y., Amartey, P.K. and Lo, A. (2016) Effect of Quercetin, Genistein and Kaempferol on Glutathione and Glutathione-Redox Cycle Enzymes in 3T3-L1 Preadipocytes. Drug and Chemical Toxicology, 39, 239-247. https://doi.org/10.3109/01480545.2015.1082135

[31] Kappus, H. (1992) Oxidative Stress in Chemical Toxicity. In: Csomós, G. and Fehér, J., Eds., Free Radicals and the Liver, Springer, Berlin, 13-20. https://doi.org/10.1007/978-3-642-76874-3_2

[32] Boadi, W.Y., Harris, S., Anderson, J.B. and Adunyah, S.E. (2013) Lipid Peroxides and Glutathione Status in Human Progenitor Mononuclear (U937) Cells Following Exposure to Low Doses of Nickel and Copper. Drug and Chemical Toxicology, 36, 155-162. https://doi.org/10.3109/01480545.2012.660947

[33] Moon, Y.J., Wang, X. and Morris, M.E. (2006) Dietary Flavonoids: Effects on Xenobiotic and Carcinogen Metabolism. Toxicology in Vitro, 20, 187-210.

https://doi.org/10.1016/j.tiv.2005.06.048 
[34] van der Sluis, A.A., Dekker, M., Verkerk, R. and Jongen, W.M.F. (200) An Improved, Rapid in Vitro Method to Measure Antioxidant Activity. Application on Selected Flavonoids and Apple Juice. Journal of Agriculture and Food Chemistry, 48, 4116-4122. https://doi.org/10.1021/jf000156i

[35] Menéndez, R., Amor, A.M., González, R.M., Jiménez, S. and Más, R. (2000) Inhibition of Rat Microsomal Lipid Peroxidation by the Oral Administration of D002. Brazil Journal of Medicine and Biological Research, 33, 85-90.

https://doi.org/10.1590/S0100-879X2000000100012

[36] Wattenberg, L.W., Page, M.A. and Leong, J.L. (1968) Induction of Increased Benzpyrene Hydroxylase Activity by Flavones and Related Compounds. Cancer Research, 28, 934-937.

[37] Conney, A.H. (2003) Enzyme Induction and Dietary Chemicals as Approaches to Cancer Chemoprevention: The Seventh DeWitt S. Goodman Lecture. Cancer Research, 63, 7005-7031.

[38] Arora, A., Nair, M.G. and Strasburg G.M. (1998) Structure-Activity Relationships for Antioxidant Activities of a Series of Flavonoids in a Liposomal System. Free Radical Biology and Medicine, 24, 1355-1363.

https://doi.org/10.1016/S0891-5849(97)00458-9 